\title{
Experimental Investigation of Lime Treated Palm Kernel Shell and Sugarcane Bagasse Ash as Partial Replacement of Coarse Aggregate and Cement Respectively in Concrete
}

\author{
Mahfouz O. A. Djima ${ }^{*}$, Geoffrey N. Mang'uriu'², John N. Mwero ${ }^{3}$ \\ ${ }^{1}$ Pan African University (PAU), Jomo Kenyatta University of Agriculture and Technology (JKUAT), Juja, Kenya \\ ${ }^{2}$ Department of Civil and Construction Engineering, Jomo Kenyatta University of Agriculture and Technology (JKUAT), \\ Juja, Kenya \\ ${ }^{3}$ Department of Civil and Construction Engineering, University of Nairobi, Nairobi, Kenya \\ Email: *marafouz@gmail.com
}

How to cite this paper: Djima, M.O.A., Mang'uriu, G.N. and Mwero, J.N. (2018) Experimental Investigation of Lime Treated Palm Kernel Shell and Sugarcane Bagasse Ash as Partial Replacement of Coarse Aggregate and Cement Respectively in Concrete. Open Journal of Civil Engineering, 8 , 358-372.

https://doi.org/10.4236/ojce.2018.84027

Received: August 1, 2018

Accepted: October 20, 2018

Published: October 23, 2018

Copyright $\odot 2018$ by authors and Scientific Research Publishing Inc. This work is licensed under the Creative Commons Attribution International License (CC BY 4.0).

http://creativecommons.org/licenses/by/4.0/ (c) (i) Open Access

\begin{abstract}
This experimental research is focused on the effect of concrete made by incorporating lime treated Palm Kernel Shell (PKS) \& Sugarcane Bagasse Ash (SCBA) as partial replacements of coarse aggregates and Ordinary Portland Cement (OPC) respectively. An experimental analysis for concrete grade 30 with a mix design ratio of 1:1.97:3.71 of cement:fine aggregates:coarse aggregates with a constant water to cement ratio of 0.5 , was used. Physical tests such as workability on fresh concrete and water absorption on hardened concrete of each batch were carried out. Mechanical tests like compressive strength and split tensile strength were carried out on hardened concrete cubes $(100 \mathrm{~mm} \times 100 \mathrm{~mm} \times 100 \mathrm{~mm})$ and cylinders $(100 \mathrm{~mm} \times 200 \mathrm{~mm})$ at 7 and 28 days. The experimental results obtained in this study indicate the possibility of using up $15 \%$ of lime treated PKS and 10\% of SCBA for production of structural concrete.
\end{abstract}

\section{Keywords}

Compressive Strength, Lime Treated Palm Kernel Shell, Split Tensile Strength, Workability, Sugarcane Bagasse Ash

\section{Introduction}

Concrete is a manmade composite material consisting of cement, aggregates and water, which is used in civil engineering construction and is preferred all over 
the world. It is the second most consumed substance on earth after water [1]. According to [2] its usage is around 10 billion tons per year, which is equivalent to 1 ton per every living person and 1.7 tons per person in the United States. About $50 \%-80 \%$ of its volume are aggregates that consist of natural crushed stones and sand. Due to the depletion of natural resources, worry is gaining place in the construction industry. In addition, since the bonding material in the concrete is cement, the high demand for this material has led to an increase in cost, making it the most expensive construction material. In view of the magnitude of these problems, combined with the problem of waste disposal, researchers decided to look for other ecological materials that could be used in the production of concrete.

The incorporation of agricultural waste material for concrete production can considerably reduce the cost incurred in buying coarse aggregate, which results in a potential reduction in the total cost of construction and will also reduce environment pollution [3]. Industrial actions produce significant quantities of non-biodegradables solid waste. Most of this waste consists of industrial waste (such as, sandpaper, chemical solvents, industrial by products, paints, paper products, metal and radioactive waste), municipal waste (such as plastics), and agricultural waste (natural fibers and such as palm kernel shell).

Palm kernel is the edible seed of the oil palm fruit. The fruit yields two distinct oils: palm oil derived from the outer parts of the fruit, and palm kernel oil derived from the kernel (FAO, 2002). Considerable amount of waste in form of PKS is generated during oil extraction. A PKS is an interesting alternative for combating problems of overexploitation of conventional aggregates in concrete whose global production increases regularly. The efforts of researchers are to achieve how to use that waste materials in concrete.

\section{Materials and Methods}

Ordinary Portland cement Type I (CEM I 42.5N) conforming to the requirements of [4] was used as a binding agent. According to [5], the treatment of PKS with lime reduce the amount of it water absorption. Hence, the Palm Kernel Shell obtained from Uganda at Kalangala island was treated with lime to make the shell less permeable. The treatment was done by putting PKS in lime solution $(40 \mathrm{~g} / \mathrm{l})$ for 2 hours follow by air drying to obtain saturated surface dried such that the water cement ratio was not affected. It met the requirement of [6]. The coarse and fine aggregate were locally obtained with nominal size of $20 \mathrm{~mm}$ for coarse aggregate and maximum size of $5 \mathrm{~mm}$ for fine aggregate. Both aggregates met the requirement of [6]. The Sugar Cane Bagasse Ash used was locally obtained from sugar manufacturing industry in Kakamega County (KENYA) and was prepared by sieving on $0.075 \mathrm{~mm}$ sieve. It met the requirement of [7]. The mix ratio of 1:1.97:3.71 for cement:fine aggregates:coarse aggregates with a constant water to cement ratio of 0.5 was used. The target grade of concrete was C30 and the specimens size used was cubes $(100 \mathrm{~mm} \times$ 
$100 \mathrm{~mm} \times 100 \mathrm{~mm})$ and cylinders $(100 \mathrm{~mm} \times 200 \mathrm{~mm})$.

\subsection{Material Characteristics}

The characteristics of PKS, SCBA, OPC, coarse and fine aggregates are in terms of Aggregate Crushing Value (ACV), Aggregate Impact Value (AIV), compressive strength, density, particle size distribution, specific gravity, splitting tensile strength, water absorption, and workability.

\subsection{Characterization of PKS, Coarse Aggregate and Fine Aggregate}

The particle size distribution of coarse aggregate and PKS are presented in Figure $1 \&$ Figure 2 . The figure shows that $90 \%$ of Coarse aggregates and PKS sizes, were between $5 \mathrm{~mm}$ to $25 \mathrm{~mm}$. Both of their curves were between upper and lower limit curve referenced in [6]. From the graph, it was noticed that the particle size of PKS are closer to upper limit envelope, which mean that the PKS has various bigger size of particles and can lead to the production of concrete with many voids, or the use of a larger portion of fine aggregate to fill those voids between the aggregates.

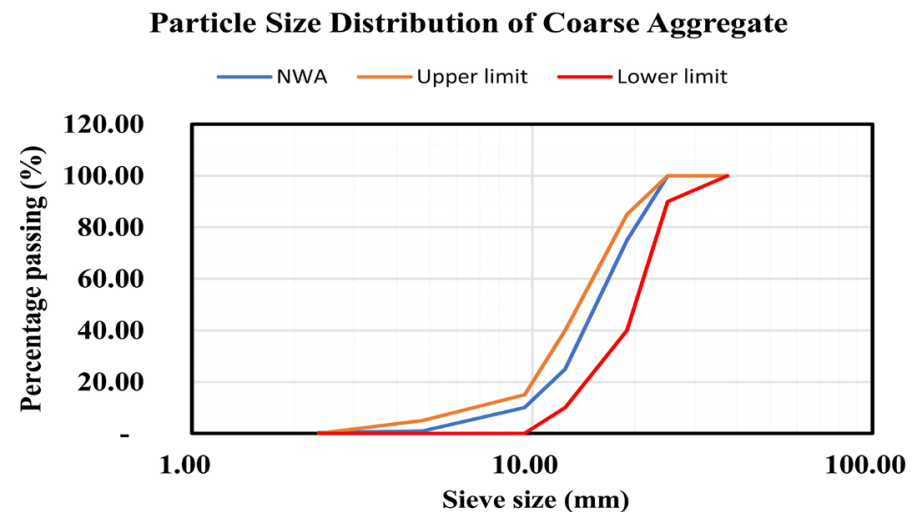

Figure 1. Particle size distribution of coarse aggregate.

Particle Size Distribution of PKS

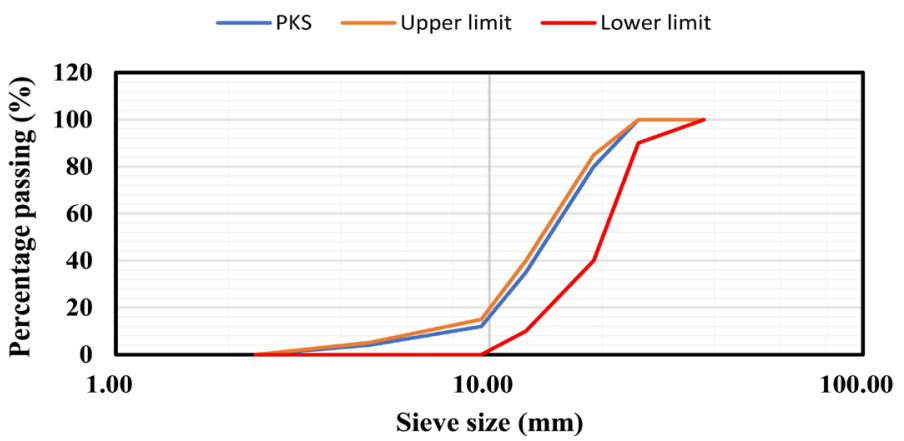

Figure 2. Particle size distribution of PKS.

As presented in Figure 3, the particles size of fine aggregates was between 0.15 to $4.75 \mathrm{~mm}$. It can be seen that the particles of fine aggregates satisfied the re- 
quirements of [6], which requires that the fine aggregate be less the $45 \%$ retained on any one sieve.

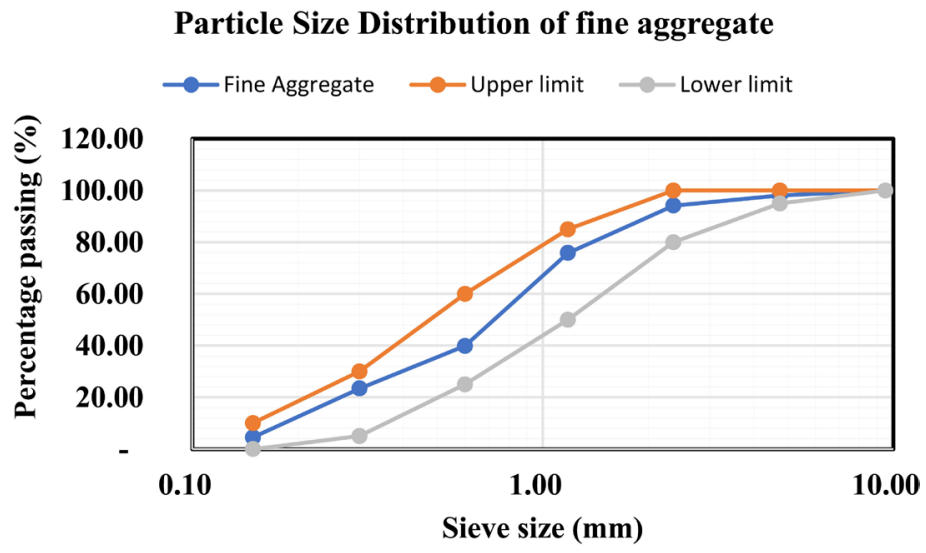

Figure 3. Particle size distribution of fine aggregate.

As shown in Table 1, although the water absorption of treated PKS is lower than untreated PKS, both are higher than the water absorption of coarse aggregate. This high-water absorption of treated PKS could lead to poor concrete workability as the quantified water for a given concrete workability might be absorbed by the PKS. The specific gravity for coarse aggregate and PKS were 2.49 and 1.01 respectively. According to [8], aggregates with specific gravity less than 2.4 are classified as light-weight aggregate (LWA). Hence, PKS can be categorized as a light-weight aggregate (LWA) since his specific gravity is less than 2.4. The ACV for coarse aggregate and PKS satisfied [9] requirement since the maximum recommended was $30 \%$. This induces that the PKS can be used for surface pavement. According to [10], the specified limit for AIV for aggregates which are adequate for concrete with good impact resistance is $25 \%$. Therefore, PKS and coarse aggregate showed better impact resistance and are in adequation with [10].

For the fine aggregate, his specific gravity was 2.45 while the fineness modulus

Table 1. Summary characteristics of PKS, coarse aggregate, and fine aggregate.

\begin{tabular}{|c|c|c|c|c|}
\hline Characteristic & Coarse aggregate & $\begin{array}{c}\text { Untreated } \\
\text { PKS }\end{array}$ & $\begin{array}{c}\text { Treated } \\
\text { PKS }\end{array}$ & Fine aggregate \\
\hline Maximum aggregate size $(\mathrm{mm})$ & 20.00 & 19.00 & 19.00 & 5.00 \\
\hline Specific gravity & 2.49 & 1.09 & 1.01 & 2.45 \\
\hline 24 hours water absorption (\%) & 3.27 & 35.64 & 30.41 & 5.26 \\
\hline Bulk density $\left(\mathrm{kg} / \mathrm{m}^{3}\right)$ & 1292.05 & 553.81 & 554.51 & 1593.25 \\
\hline Loose density $\left(\mathrm{kg} / \mathrm{m}^{3}\right)$ & 1177.05 & 480.52 & 481.42 & 1474.83 \\
\hline Aggregate crushing value, ACV (\%) & 20.83 & 5.37 & 5.43 & - \\
\hline Aggregate impact value, AIV (\%) & 8.15 & 6.51 & 6.77 & - \\
\hline Fineness modulus & - & - & - & 2.55 \\
\hline
\end{tabular}


was 2.55. This fineness modulus satisfied the requirement of [6] since. It is suggested that the fineness modulus be kept between 2.3 and 3.1. This is due to the fact that a "very fine" fine aggregate will increase water demand on the mix, while a "very coarse" fine aggregate could compromise workability. Hence, the fineness modulus results obtained shows that the material was not very fine and not very coarse either, and therefore suitable for the production of concrete with high workability and finish-ability.

\subsection{Characteristics of Sugarcane Bagasse Ash and Ordinary Portland Cement}

The maximum particle size of SCBA used in this research was $0.075 \mathrm{~mm}(75 \mu \mathrm{m})$. Its hydrometer analysis result is presented in Figure 4. From the Figure, about $28 \%$ of it particles were between $0.002 \mathrm{~mm}(2 \mu \mathrm{m})$ to $0.02 \mathrm{~mm}(20 \mu \mathrm{m})$, and $72 \%$ between $0.02 \mathrm{~mm}(20 \mu \mathrm{m})$ to $0.065 \mathrm{~mm}(65 \mu \mathrm{m})$. Due to this finesse particle, the surface area and water demand of SCBA improved. In terms of specific gravity, the SCBA and OPC were 2.00 and 3.09 respectively. Due to the fact that the specific gravity was below 2.40 , it can be said that the SCBA used in this research was lightweight material [8]. The low specific gravity of SCBA can contribute in the reduction of concrete density.

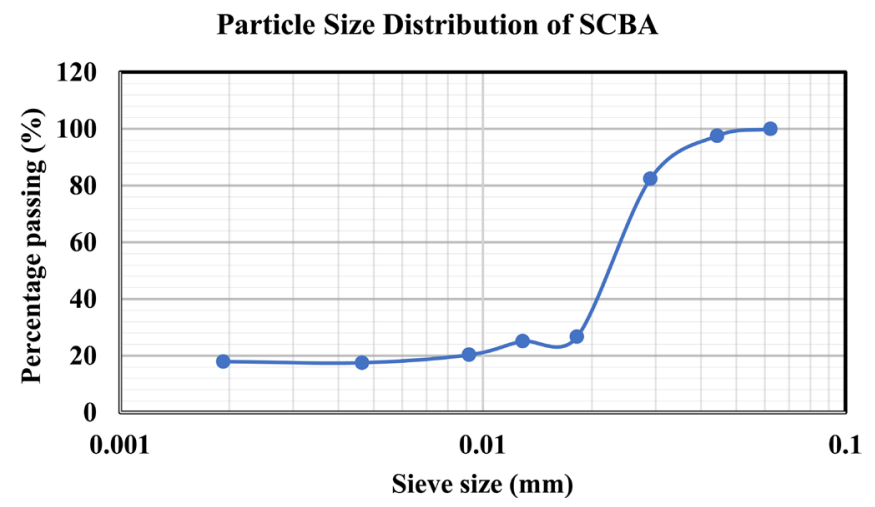

Figure 4. Particle size distribution of SCBA.

\subsection{Chemical Analysis of Sugarcane Bagasse Ash and Ordinary Portland Cement}

As shown in Table 2, the silica $\left(\mathrm{SiO}_{2}\right)$ content of SCBA is $297 \%$ higher than that of cement while the free lime content $(\mathrm{CaO})$ of cement is higher than SCBA by $94.86 \%$. Despite this, we noted that the SCBA satisfied the minimum requirement of [7] which required $70 \%$ for a good pozzolana.

Therefore, the presence of silica and alumina above the minimum requirement for a good pozzolana shows the ability of the SCBA to form cementitious compound when mixed with the free lime of the OPC in the presence of moisture. Calcium oxide is required for the formation of Tricalcium silicate and Dicalcium silicate which both reacts with water to form Calcium silicate hydrate which gives concrete its strength. 
Table 2. Chemical properties of SCBA and OPC.

\begin{tabular}{ccc}
\hline Chemical composition & \multicolumn{2}{c}{ Content (\%) } \\
\cline { 2 - 3 } & SCBA & OPC \\
\hline Silica $\left(\mathrm{SiO}_{2}\right)$ & 87.35 & 22.00 \\
Aluminum $\left(\mathrm{Al}_{2} \mathrm{O}_{3}\right)$ & 1.97 & 4.80 \\
Calcium Oxide $(\mathrm{CaO})$ & 3.03 & 59.00 \\
Magnesium Oxide $(\mathrm{MgO})$ & 0 & 0.75 \\
Potassium Oxide $\left(\mathrm{K}_{2} \mathrm{O}\right)$ & 4.46 & 0.60 \\
Manganese Oxide $(\mathrm{MnO})$ & 0.24 & 0.04 \\
Titanium Oxide $\left(\mathrm{TiO}_{2}\right)$ & 0.18 & 0.20 \\
\hline
\end{tabular}

\section{Results and Discussion}

\subsection{Workability of Lime Treated PKS and SCBA Concrete}

Workability in terms of slump test is presented in Figures 5-7. From Figure 5, though the PKS was treated with lime to reduce the water absorption, there was still a reduction in slump with increase in PKS content. The workability reduced from $27 \mathrm{~mm}$ for the control mix to $20 \mathrm{~mm}$ for $20 \%$ addition of PKS. This might have been due to the finer particle sizes of PKS when compared to the coarse aggregate. From Figure 6, the presence of SCBA in the mix resulted in increased amount of fines as seen by the Particle Size Distribution curve of the SCBA concrete mix which increased the water demand for the mix. It confirms to the fact that pozzolanic reactions require more water as compared to normal concrete made with OPC. This finding is consistent with the research outcomes [11], which reported the reduction in slump with increase in percentage of SCBA.

As presented in Figure 7, it can be seen that the workability of lime treated PKS \& SCBA concrete decreased at all mixes when compare to normal weight concrete. The lowest workability recorded falls in the very low range $(0-25 \mathrm{~mm})$. The decrease in workability of lime treated PKS \& SCBA concrete can be seen to be

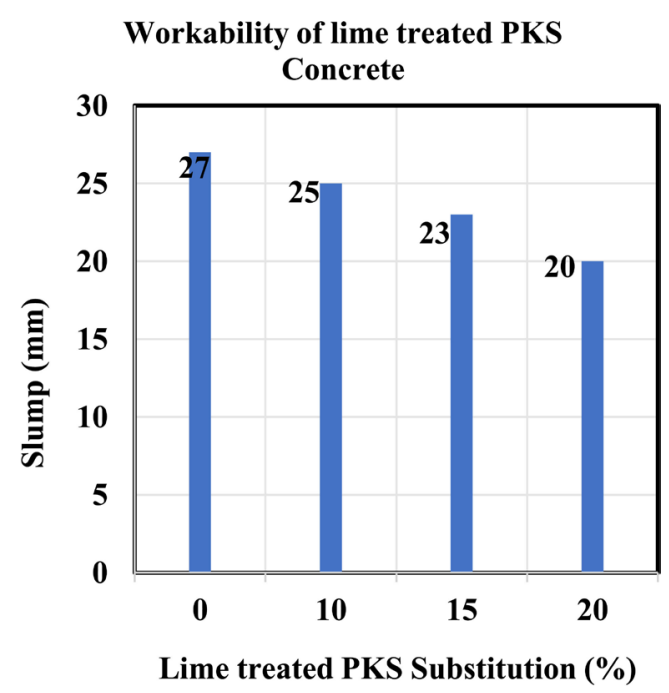

Figure 5. Workability of lime treated PKS concrete. 


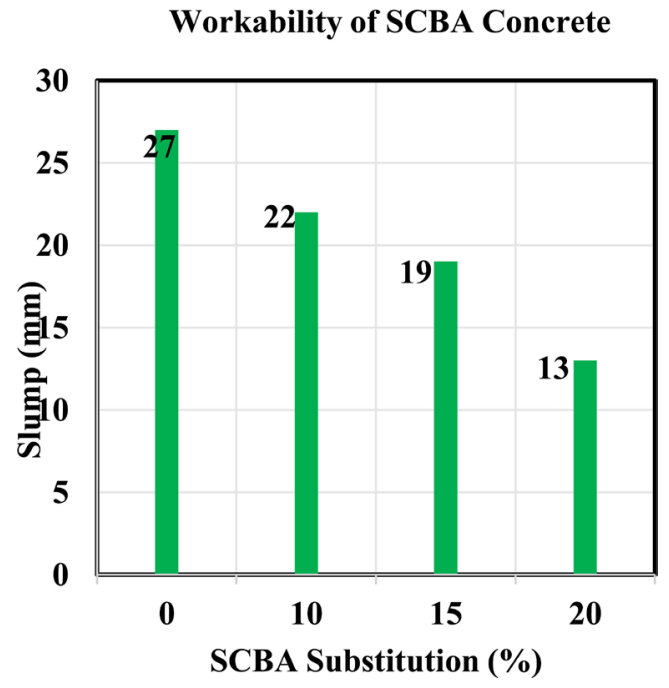

Figure 6. Workability of SCBA concrete.

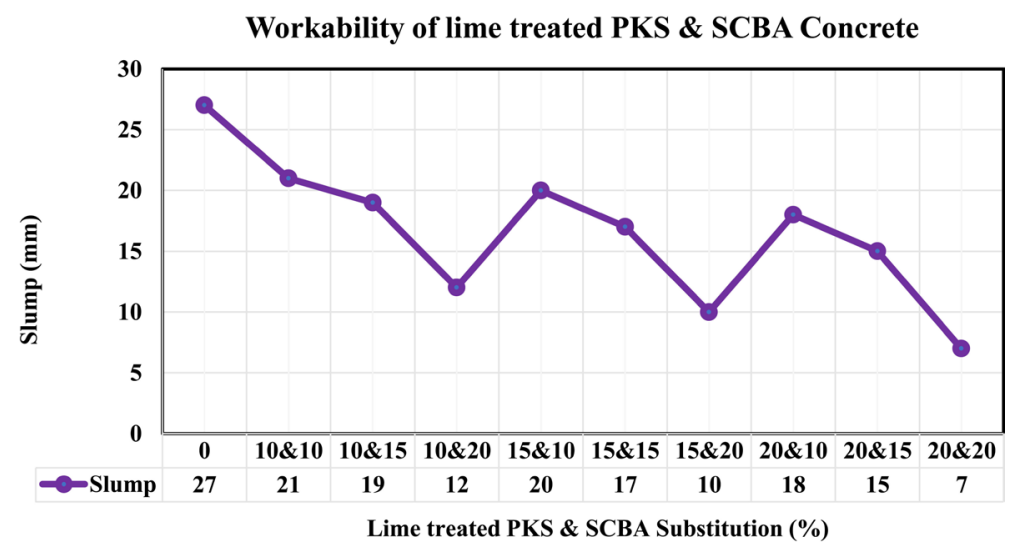

Figure 7. Workability of lime treated PKS \& SCBA concrete.

linear and proportional to the percentages of lime treated PKS \& SCBA added to the mix. This can be attributed to high water absorption of PKS as compared to the coarse aggregate and hence demanding more water for a good workability. It can also be attributed to SCBA, as it particle sizes was very fine $(75 \mu \mathrm{mm})$, hence increase in the amount of fines in the mix as compared to the OPC.

Hence, decrease in workability with increase in lime treated PKS \& SCBA might require more compacting efforts which can lead to poor compaction. Poor compaction thus leads to leaving voids in the concrete which can cause reduction in concrete strength, density, and durability. Also, poor compacted concrete can increase the water absorption of concrete which affects concrete durability. Consequently, when using both lime treated PKS \& SCBA, superplasticizers should be used in order to improve the workability of the concrete.

\subsection{Water Absorption of Lime Treated PKS and SCBA Concrete}

The water absorption of lime treated PKS concrete increased slightly as the percentage replacement of lime treated PKS increase as shown in Figure 8. At 0\% 
the water absorption was $1.72 \%$, which increased to $3.74 \%$ at $20 \%$ PKS addition. This reduction in workability can be attributed to increase in the water absorption of the mix which must have resulted in the presence of voids in the hardened concrete. It is in order with the report of [12]. Similar result was obtained from Figure 9 for SCBA concrete which shows a rise in the water absorption of concrete as the percentage of SCBA increases from $1.72 \%$ in the control to $2.80 \%$ at $20 \%$ SCBA content. This is due to the high absorptivity characteristic of SCBA as it particles was very fine.

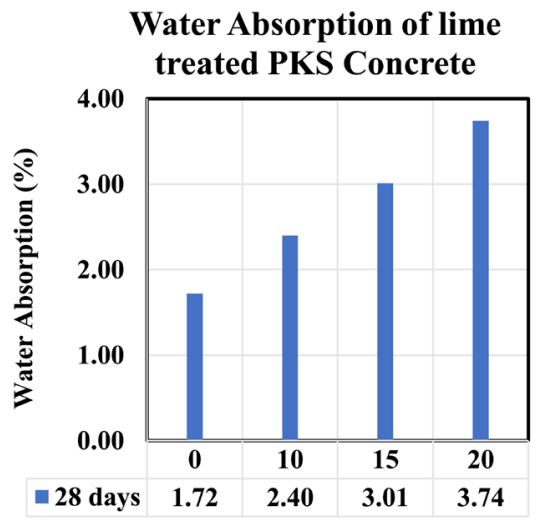

Lime treated PKS Substitution (\%)

Figure 8. Water absorption of lime treated PKS concrete.

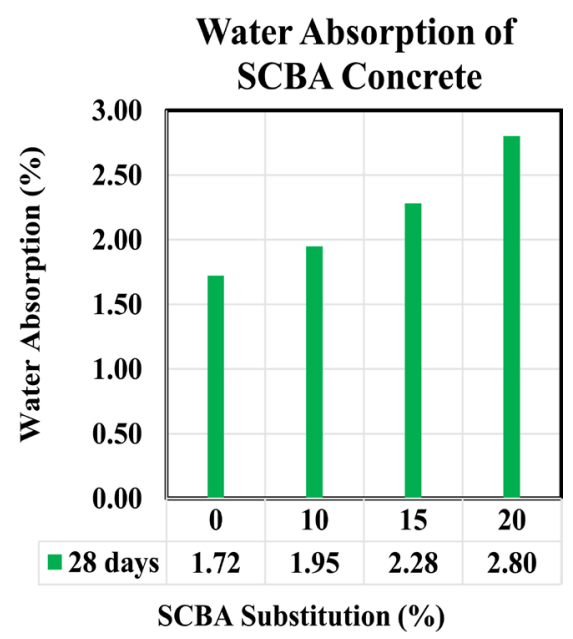

Figure 9. Water absorption of SCBA concrete.

As presented graphically in Figure 10, the results indicate that adding lime treated PKS \& SCBA to concrete increases its water absorption: As recorded, there was a sudden increase in the water absorption of lime treated PKS \& SCBA concrete from $1.72 \%$ to $7.40 \%$ noticed at $20 \%$ replacement of SCBA \& PKS. This can be attributed to the combined high absorption characteristic of PKS \& SCBA compared to coarse aggregate and OPC respectively. According to [13] the water absorption of concrete by immersion is an important property that gives an indirect indication of the pore structure of the concrete and durability perfor- 
mance in corrosive environment. Hence, high water absorption of lime treated PKS \& SCBA can lead to less durable concrete.

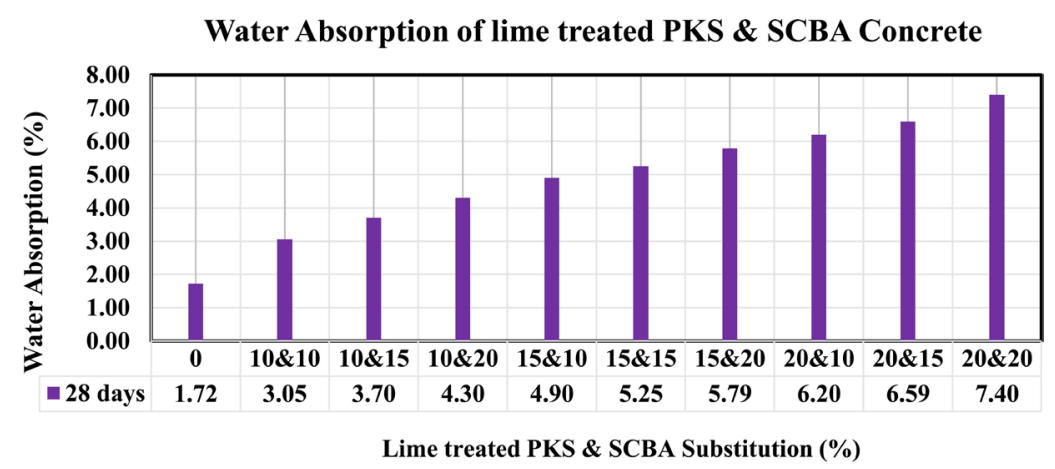

Figure 10. Water absorption of lime treated PKS and SCBA concrete.

\subsection{Density of Lime Treated PKS and SCBA Concrete}

The hardened bulk density of all lime treated PKS concrete and SCBA concrete prepared in this study are graphically presented in Figure $11 \&$ Figure 12 . The density of lime treated PKS concrete increased from 7 days to 28 days while decreased as the percentage of substitution increased. This can be attributed to the low specific gravity of PKS which lead to porous concrete and can reduce the compressive strength. Similar results were observed on density of SCBA concrete. It could be as a result that SCBA having a less bulk density of $554.13 \mathrm{~kg} / \mathrm{m}^{3}$ as compared to that of OPC which was $1396.67 \mathrm{~kg} / \mathrm{m}^{3}$. It is consistent with [11] who reported, the average density of concrete decreases with increase in percentage replacement of SCBA with cement.

From Figure 13, the hardened density of lime treated PKS \& SCBA concrete increased from 7 to 28 days, although a decrease was noticed with increase in the percentage replacement. This reduction is expected as the constituent materials were observed to be lighter than their replacements. Also, it can be said that because of the reduction in slump, there must have been poor compaction which

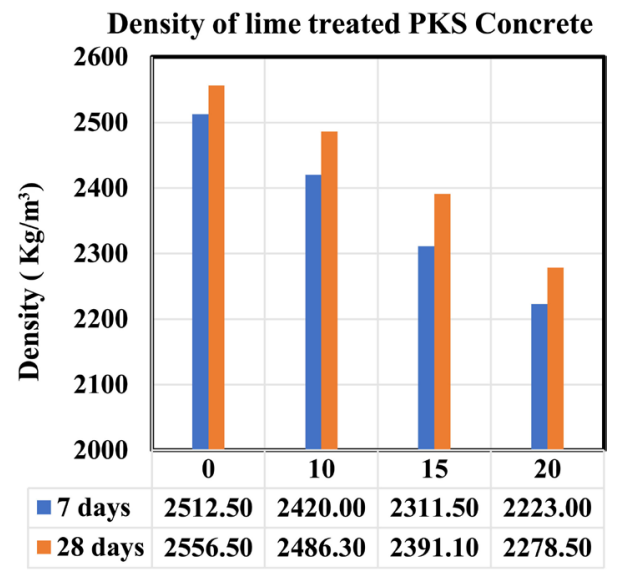

Lime treated PKS Substitution (\%)

Figure 11. Density of lime treated PKS concrete. 


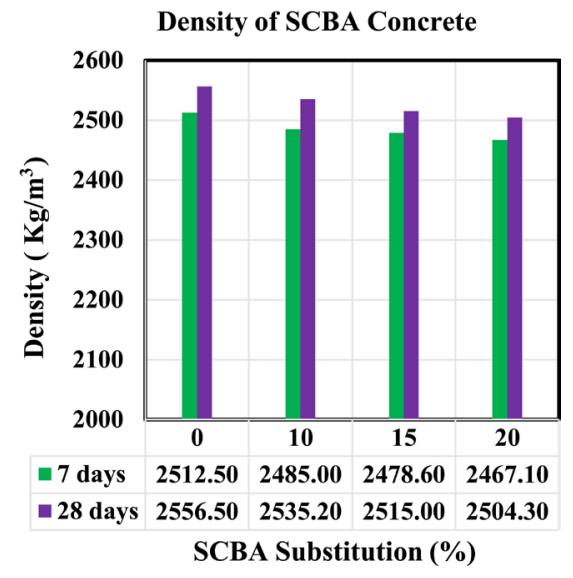

Figure 12. Density of SCBA concrete.

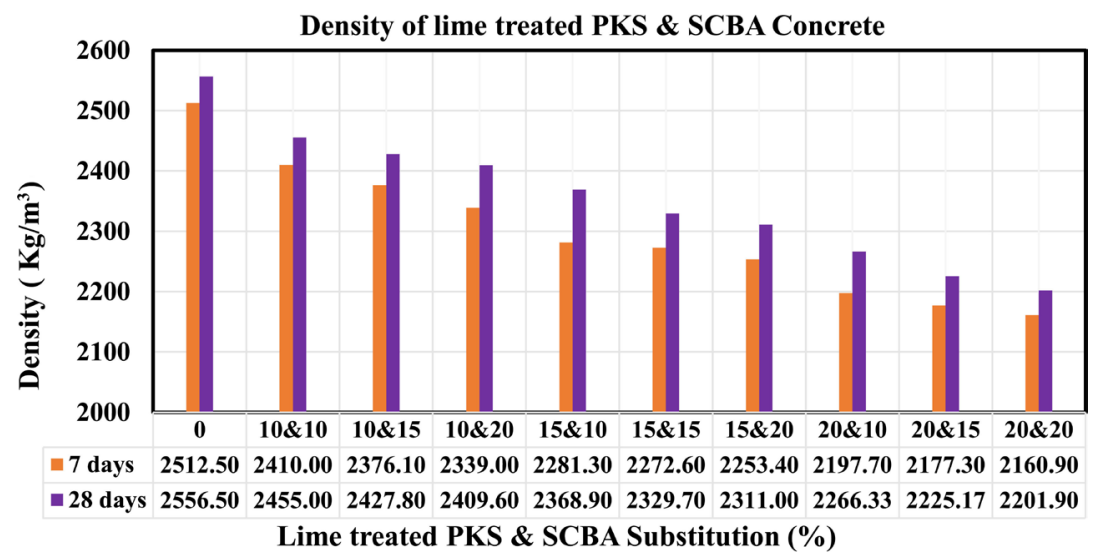

Figure 13. Density of lime treated PKS \& SCBA Concrete.

could have resulted in voids in the concrete and hence reducing its density. This observed reduction in concrete density might result in a lower concrete strength, as concrete density contributes to concrete compressive strength. The lime treated PKS \& SCBA concrete can be classified as normal weight concrete as the highest density is $\left(2556.50 \mathrm{~kg} / \mathrm{m}^{3}\right)$ while the lowest is $\left(2201.90 \mathrm{~kg} / \mathrm{m}^{3}\right)$, which is outside the range of structural lightweight concrete.

\subsection{Compressive Strength of Lime Treated PKS and SCBA Concrete}

Compressive strength is the capacity of a material or structure to withstand loads tending to reduce size. The compressive strength of concrete is one of the most important and useful properties of concrete. In most structural applications, concrete is used primarily to resist compressive stresses. It is obtained by dividing the maximum load applied to the cube by the cross-sectional area [14]. From the experimental investigation, the compressive strength of lime treated PKS concrete (Figure 14) shows that the concrete gains strength with an increase in the curing age as the 7 days strength was lower than 28 days but decreases with an increase in PKS replacement. It could be noticed that the control mix has the highest compressive strength. The compressive strength decreased at respective 
percentages of $11.19 \%, 31.37 \%$ and $40.57 \%$ for $10 \%, 15 \%$ and $20 \%$ respectively compare to the control.

From Figure 15, the reduction in compressive strength of SCBA concrete can be attributed to the significantly low calcium oxide content of bagasse ash $(3.03 \%)$ compared to that of cement $(59.0 \%)$. Calcium oxide is required for the formation of Tricalcium silicate and Dicalcium silicate which both reacts with water to form Calcium silicate hydrate which gives concrete its strength.

Tricalcium silicate + Water $\rightarrow$ Calcium silicate hydrate + Calcium hydroxide + heat

Dicalcium silicate + Water $\rightarrow$ Calcium silicate hydrate + Calcium hydroxide + heat

The reaction of Tricalcium silicate is fast as it is responsible for most of the early 7 days strength. From Figure 15 the reaction gave concrete $74.39 \%, 73.67 \%$ and $73.81 \%$ of the 28 days strength for $10 \%, 15 \%$ and $20 \%$. Dicalcium silicate reacts more slowly and contributes only little to the strength at later times. Similar reduction in compressive strength of SCBA concrete was reported by [11] [15].

As presented in Figure 16, for each curing age and increasing PKS \& SCBA content in concrete mix, the result shows a decreasing compressive strength value below that of the control. At 28 days, the compressive decreased from 30.44 $\mathrm{MPa}$ to $15.43 \mathrm{MPa}$ for $20 \%$ PKS \& SCBA incorporation. The reduction can be attributed to the increased surface area of PKS as it was finer than the coarse

\section{Compressive Strength of lime} treated PKS Concrete

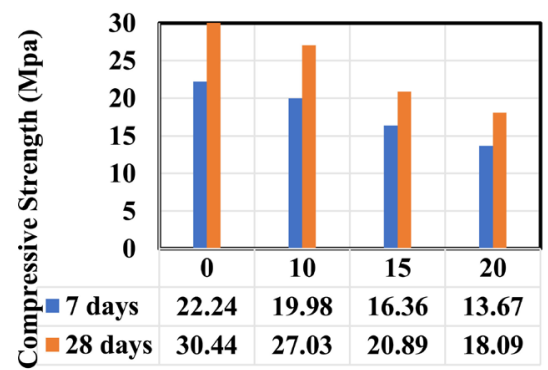

Lime treated PKS Substitution (\%)

Figure 14. Compressive strength of lime treated PKS concrete.

\section{Compressive Strength of} SCBA Concrete

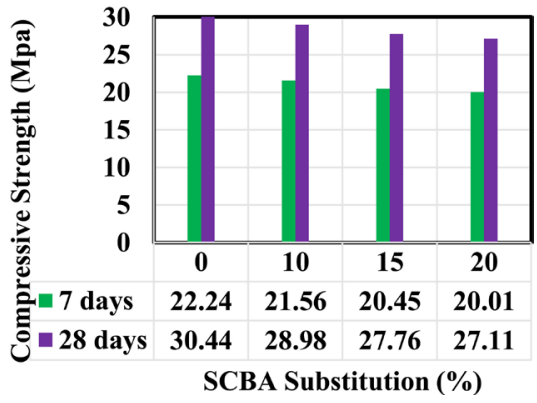

Figure 15. Compressive strength of SCBA concrete. 


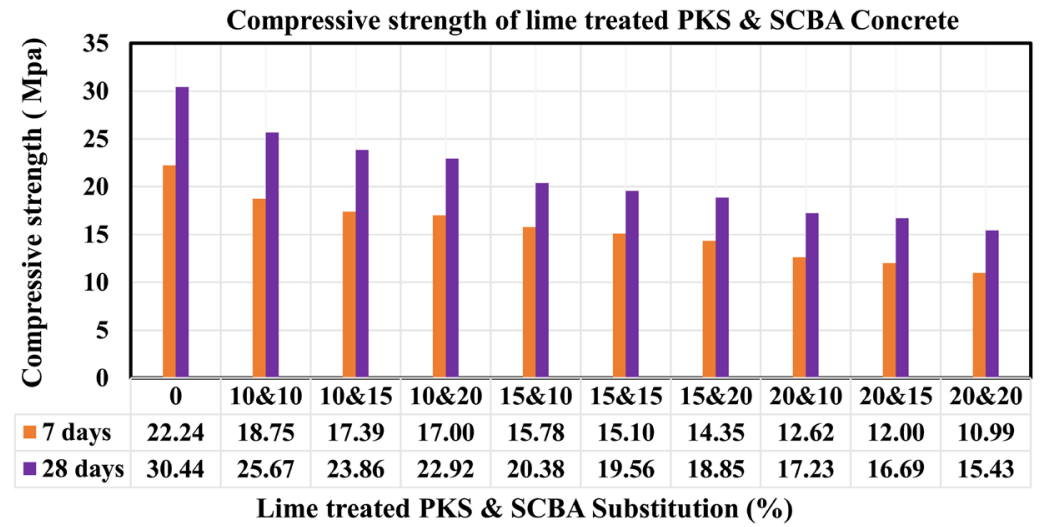

Figure 16. Compressive strength of lime treated PKS and SCBA concrete.

aggregates thereby resulting into weak bonding as more cement paste might have been demanded. Again, since lime-pozzolana reactions required time, it could be that the 28 days curing period was not sufficient for the full development of the strength and thus resulting in the reduction of the compressive strength. According to [16] a compressive strength within the range of 20 to $45 \mathrm{MPa}$ is classified as good for normal weight concrete. Hence up to $15 \%$ of lime treated PKS and $10 \%$ of SCBA can be used as partial replacement of coarse aggregate and $\mathrm{OPC}$ respectively in production of structural concrete.

\subsection{Splitting Tensile Strength of Lime Treated PKS and SCBA Concrete}

The tensile strength of concrete is one of the basic and important properties which greatly affect the extent and size of cracking in structures. Concrete develops cracks when tensile forces exceed its tensile strength. A tensile strength is a measure of the ability of material to resist a force that tends to pull it apart. It is expressed as the minimum tensile stress (force per unit area) needed to split the material apart. As portrayed in Figure 17 \& Figure 18 the evolution of splitting tensile strength, the experimental results show a trend that resembles the compressive strength results. The Splitting tensile strength of lime treated PKS concrete and SCBA concrete decreased as increased in percentage replacement while increased in curing age. This reduction can be attributed to poor compaction, increased surface area of the lime treated PKS, reduced bonding properties of SCBA in constituent materials in concrete as compared to the cement. This is in concordance with result reported by [15].

From Figure 19, the splitting tensile strength decreased from 3.00 MPa for the control to $1.77 \mathrm{MPa}$ for 20\% PKS \& SCBA. Increase in the percentage of lime treated PKS \& SCBA contents resulted in the reduction of the splitting tensile strength while there was an increase in the splitting tensile strength with curing age. This reduction can be caused by high water absorption characteristics of PKS and SCBA which lead to poor workability by creating voids in concrete. It is also due to lower specific gravity of PKS and SCBA which lead to lower concrete 
density as compare to control.

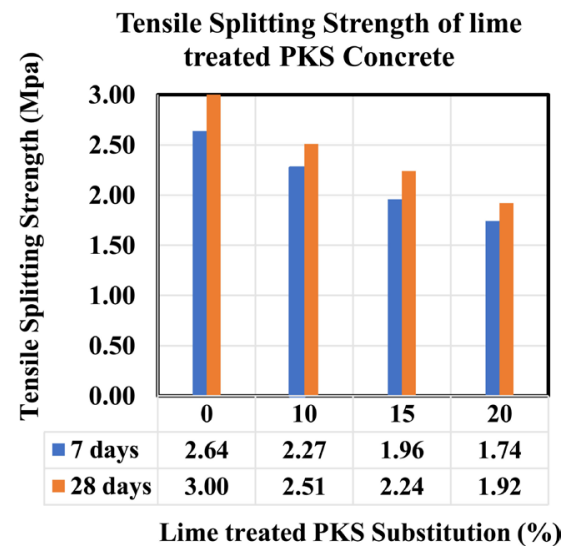

Figure 17. Tensile splitting strength of lime treated PKS concrete.

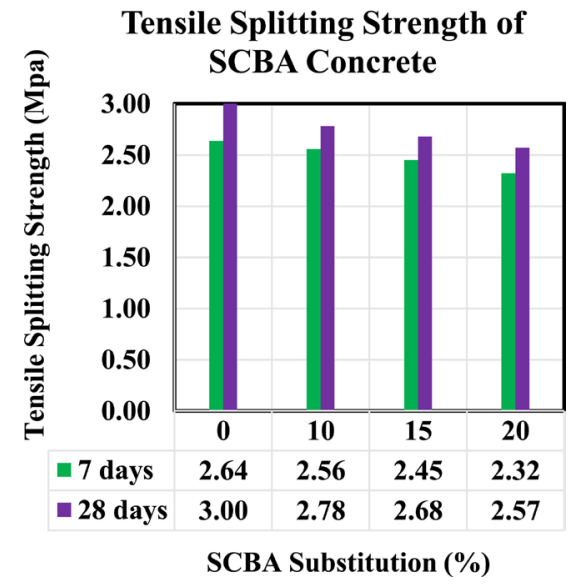

Figure 18. Tensile splitting strength of SCBA concrete.

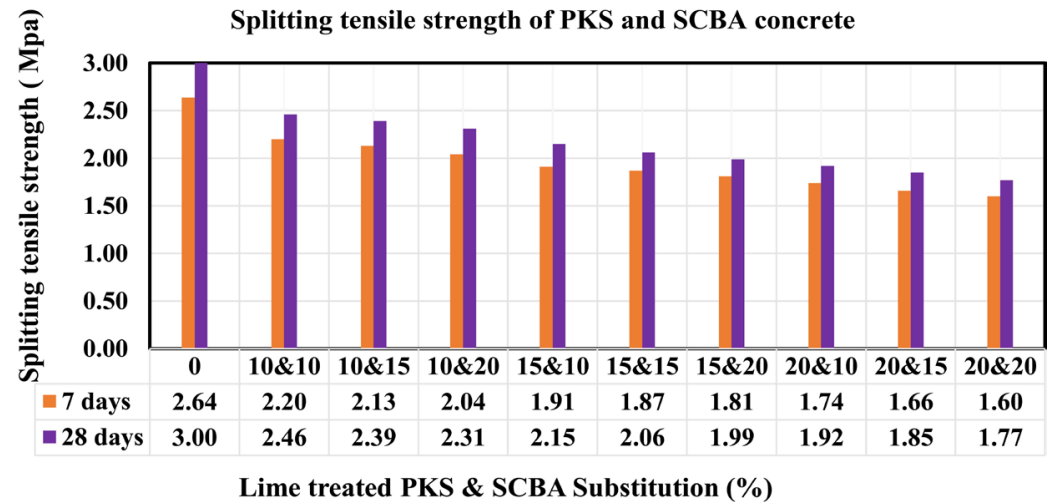

Figure 19. Splitting tensile strength of PKS and SCBA concrete.

\section{Conclusions and Recommendations}

\subsection{Conclusions}

From the experimental investigation of this research, the following conclusion can be made. 
- The PKS satisfied the ASTM C-33 requirement in terms of particles size distribution and can be used as replacement of coarse aggregate;

- The chemical composition of SCBA satisfied the requirement ASTM C618 for a good pozzolana and can be used as partial replacement of OPC;

- The superplasticizer should be used to improve the workability of lime treated PKS \& SCBA fresh concrete;

- The low specific gravity of PKS and SCBA led to reduction in concrete density as the PKS and SCBA increased in the mix;

- The reduction in compressive strength and splitting tensile strength of lime treated PKS \& SCBA concrete;

- Increasement of water absorption of concrete as the lime treated PKS \& SCBA increased in the mix.

\subsection{Recommendations}

From the study, the following recommendations will be suggested:

- Used up $15 \%$ of lime treated PKS and 10\% of SCBA for production of structural concrete. It will help in preservation of natural resources by reducing high demand of coarse aggregate and OPC;

- Extend compressive strength test up to 90 days to follow the strength development over time, as the pozzolanic (SCBA) reaction is a long-term reaction;

- Durability test, such as chemical resistance should be made on lime treated PKS and SCBA concrete to see the effect in aggressive environment.

\section{Conflicts of Interest}

The authors declare no conflicts of interest regarding the publication of this paper.

\section{References}

[1] Gagg, C.R. (2014) Cement and Concrete as an Engineering Material: An Historic Appraisal and Case Study Analysis. Engineering Failure Analysis, 40, 114-140. https://doi.org/10.1016/j.engfailanal.2014.02.004

[2] Tinni, A. and Consulting, T.M. (2013) Introduction to Concrete Pavements. 1-9.

[3] Philips, E.S., Mutuku, R.N. and Mwero, J.N. (2017) Effects of Palm Kernel Shell and Rice Husk Ash as Partial Replacements of Normal Weight Aggregate and Ordinary Portland Cement in Concrete. European International Journal of Science and Technology, 6, 42-54.

[4] EN, B.S. (2011) "197-1: 2011", Cem. Compos. Specif. Conform. Criteria Common Cem. Engl. Br. Stand. Inst., London.

[5] Traore, Y., Messan, A., Tsobnang, F. and Gerard, J. (2014) Influence du traitement des coques de noix de palme sur les propriétés physico-mécaniques des bétons légers. Conférence Matériaux 2014-Colloque Ecomatériau, November 2014, Montpellier, 4.

[6] ASTMC-33 (2011) Concrete Aggregates.

[7] ASTM-C618 (2005) Stand. Specif. Coal Fly Ash Raw Calcined Nat. Pozzolan Use 
Concr.

[8] Popovics, S. (1992) Concrete Materials: Properties Specifications, and Testing. Noyes Publications.

[9] BS 812-110 (1990) Testing Aggregates. BS 812 Part 110.

[10] BS 812-112 (1990) Testing Aggregates. BS 812 Part 112.

[11] Abdulkadir, T.S., Oyejobi, D.O. and Lawal, A.A. (2014) Evaluation of Sugarcane Bagasse Ash as a Replacement for Cement in Concrete Works. ACTA TECHNICA CORVINIENSIS - Bulletin of Engineering, 7, 71.

[12] Olanipekun, E.A., Olusola, K.O. and Ata, O. (2006) A Comparative Study of Concrete Properties Using Coconut Shell and Palm Kernel Shell as Coarse Aggregates. Building and Environment, 41, 297-301. https://doi.org/10.1016/j.buildenv.2005.01.029

[13] De Schutter, G. and Audenaert, K. (2004) Evaluation of Water Absorption of Concrete as a Measure for Resistance against Carbonation and Chloride Migration. Materials and Structures, 37, 591. https://doi.org/10.1007/BF02483288

[14] BS 1881-116 (1983) Testing Concrete. Method for Determination of Compressive Strength of Concrete Cubes. BSI, London.

[15] Modani, P.O. and Vyawahare, M.R. (2013) Utilization of Bagasse Ash as a Partial Replacement of Fine Aggregate in Concrete. Procedia Engineering, 51, 25-29.

[16] MacGregor, J.G., Wight, J.K., Teng, S. and Irawan, P. (1997) Reinforced Concrete: Mechanics and Design. Vol. 3, Pearson, Prentice Hall, Upper Saddle River, NJ. 